\title{
Originals
}

\section{Diurnal Variations in Blood Intermediary Metabolites in Mild Gestational Diabetic Patients and the Effect of a Carbohydrate-Restricted Diet}

\author{
J. M. Potter, J.P. D. Reckless and D. R. Cullen \\ Royal Hallamshire Hospital, Sheffield, UK
}

Summary. Twenty-four-hour metabolic profiles were performed in the third trimester of pregnancy in seven non-diabetic women (group A) and in two groups of mild gestational diabetics, at diagnosis (group B, seven patients) and after treatment with a 150 -g carbohydrate diet (group C, seven patients). Mean 24-h blood metabolite levels ( \pm SD) in groups $A, B$ and $C$ were: glucose: $4.65 \pm 0.82,5.35 \pm 3.06$ and $5.40 \pm$ $1.7 \mathrm{mmol} / 1$; lactate: $1.05 \pm 0.18,1.14 \pm 0.42$ and 0.78 $\pm 0.22 \mathrm{mmol} / 1$; alanine: $0.31 \pm 0.03,0.31 \pm 0.10$ and $0.27 \pm 0.07 \mathrm{mmol} / 1$; ketone bodies: $0.11 \pm 0.04,0.19$ \pm 0.05 and $0.26 \pm 0.15 \mathrm{mmol} / 1$. Glucose levels were not significantly different between the groups. Ketone body levels were elevated in the diabetics prior to treatment $(p<0.01)$ and rose higher on diet. Lactate levels were reduced on the diet $(0.05<p<0.10)$. Abnormalities in the concentrations of total blood ketone body levels in gestational diabetics may be detrimental to fetal development and therapy should be designed to minimise changes in intermediary metabolites.

Key words: Pregnancy in diabetes, gestational diabetes, diabetic diet, metabolism, gluconeogenesis, lipid mobilisation, glycolysis, glucose, lactate, alanine, total ketone bodies, acetoacetate, 3 hydroxybutyrate.

Gestational diabetes has been associated with increased perinatal mortality and morbidity rates [1-4] although the rise in mortality is not confirmed in all studies [5]. Although hyperglycaemia in the mother is an important contributory factor [6], it is possible that disturbances of non-esterified fatty acids [7], 3-hydroxybutyrate [8] and amino acids [9] may also be significant factors, particularly since some of these metabolites correlate better with such characteristic changes in the infant as increased birth weight $[10,11]$ than does maternal hyperglycaemia [12].

These gestational diabetics are frequently treated initially by diet [13], using calorie and carbohydrate restriction and this is often sufficient to control blood glucose levels. We were interested in the effect of dietary treatment on other metabolites which might influence fetal development and have therefore measured the levels of blood glucose and other major intermediary metabolites over $24 \mathrm{~h}$ during late pregnancy in gestational diabetics before and after treatment with a 150 -g carbohydrate diet. The results were compared with similar measurements in a group of normal non-diabetic women of the same gestational age.

\section{Subjects and Methods}

\begin{abstract}
Subjects
Three groups of women were studied (Table 1) who were of similar age, weight, percentage desirable body weight, parity and gestational age at the time of study. Group A consisted of seven women with normal oral glucose tolerance in the third trimester. Their pregnancies were uncomplicated apart from suspected placenta praevia without bleeding in three cases, mild hypertension resolving on bed rest in one, and one woman with fetal growth retardation in a previous pregnancy.

Two groups of women with gestational diabetes were studied. The first diabetic group (group B) included seven women referred from the antenatal clinic with suspected gestational diabetes and studied at the time of diagnosis prior to any dietary treatment. The second group (group C) included seven women studied after treatment with a $150-\mathrm{g}$ carbohydrate-restricted diet. Four of the gestational diabetic women were studied before and after dietary treatment and are included in both groups B and C. Patients in all groups had previously normal obstetric histories. Patients in groups $\mathrm{B}$ and $\mathrm{C}$ had normal glucose tolerance 6 weeks postpartum. In all patients studied, informed consent was obtained and the work had Ethical Committee approval.
\end{abstract}


Table 1. Clinical details of the three groups of women studied

\begin{tabular}{lllllll}
\hline & $\begin{array}{l}\text { No. of patients } \\
\text { studied }\end{array}$ & Age (years) & Weight (kg) & $\begin{array}{l}\text { \% Desirable body } \\
\text { weight }^{\mathrm{a}}\end{array}$ & $\begin{array}{l}\text { Parity } \\
\text { (infants/ } \\
\text { group) }\end{array}$ & Gestational age (weeks) \\
\hline Group A & 7 & $28 \pm 2.0$ & $65 \pm 9.4$ & $110 \pm 19.3$ & 4 & $34 \pm 2.2$ \\
Group B & 7 & $27 \pm 7.8$ & $68 \pm 13.7$ & $112 \pm 17.8$ & 6 & $32 \pm 5.0$ \\
Group C & 7 & $27 \pm 6.9$ & $67 \pm 13.6$ & $114 \pm 18.4$ & 4 & $34 \pm 4.2$ \\
\hline
\end{tabular}

Results expressed as mean \pm SD

"Percent of desirable weight was calculated using pre-pregnant weights from the tables of the Metropolitan Life Insurance Society [29] Group A:non-diabetic women; group B: gestational diabetics before treatment; group C: gestational diabetics controlled on a 150 $\mathrm{g}$ carbohydrate diet

Table 2. Blood glucose, lactate, alanine and total ketone body levels during $24 \mathrm{~h}$ in the three groups of women studied

\begin{tabular}{lllll}
\hline & $\begin{array}{l}\text { Blood glucose } \\
(\mathrm{mmol} / \mathrm{l})\end{array}$ & $\begin{array}{l}\text { Blood lactate } \\
(\mathrm{mmol} / \mathrm{l})\end{array}$ & $\begin{array}{l}\text { Blood alanine } \\
(\mathrm{mmol} / \mathrm{l})\end{array}$ & $\begin{array}{l}\text { Blood total ketone bodies } \\
(\mathrm{mmol} / \mathrm{l})\end{array}$ \\
\hline Group A & $4.65 \pm 0.82$ & $1.05 \pm 0.18$ & $0.31 \pm 0.03$ & $0.11 \pm 0.04$ \\
Group B & $5.35 \pm 3.06$ & $1.14 \pm 0.42$ & $0.31 \pm 0.10$ & $0.19 \pm 0.05^{\mathrm{b}}$ \\
Group C & $5.40 \pm 1.74$ & $0.78 \pm 0.22^{\mathrm{a}}$ & $0.27 \pm 0.07$ & $0.26 \pm 0.15$ \\
\hline
\end{tabular}

Results expressed as mean $\pm \mathrm{SD}$. Groups as in Table 1

${ }^{a} p<0.10$ compared with group B

${ }^{b} p<0.01$ compared with group A

\section{Definitions}

The diagnosis of gestational diabetes was based on the recommendations of the British Diabetic Association [14] and of Hadden [15], using a standard 50-g oral glucose tolerance test with venous blood samples. Tests were regarded as abnormal if either the fasting blood glucose or the $2-\mathrm{h}$ blood glucose level was $>6.7 \mathrm{mmol} / \mathrm{l}$. Only those gestational diabetics with normal fasting glucose levels and raised 2-h glucose levels were included in this study. The mean glucose levels for each group at 0 and $120 \mathrm{~min}$ after oral glucose were for group A: $3.8 \pm 0.6$ and $4.7 \pm 1.1 \mathrm{mmol} / \mathrm{l}$; group B: $4.6 \pm$ 1.3 and $7.9 \pm 0.7 \mathrm{mmol} / 1$, group C: $5.0 \pm 0.9$ and $8.1 \pm 0.5 \mathrm{mmol} / 1$.

\section{Protocol}

Women in groups A and B did not restrict their diets before or during the study and each woman had an oral glucose tolerance test performed within 1 week of the study. Women in group $C$ were on a $150 \mathrm{~g}$ carbohydrate diet at home before the study. The diet was given as $30 \mathrm{~g}$ at breakfast, $40 \mathrm{~g}$ at lunch and supper and $10 \mathrm{~g}$ at each snack time at mid-morning, mid-afternoon and before bed. The remaining $10 \mathrm{~g}$ was taken as milk throughout the day. Dietary advice was given and regularly reinforced by a trained dietitian and maintained on the ward during the metabolic profile. Whilst direct control of dietary intake as an outpatient was not possible, compliance in these pregnant diabetic subjects was thought to be good. The mean calorie intake of $2200 \mathrm{kcal}$ (range approximately $1,900-2,600 \mathrm{kcal}$ ) was maintained at the pre-treatment level as carbohydrate intake was controlled.

A 24-h metabolic profile was obtained in each of the women who were admitted overnight prior to the study. The women were permitted to be ambulant during the study other than for $5 \mathrm{~min}$ rest prior to sampling. Samples were obtained from an indwelling cannula kept patent with normal saline, and blood was taken hourly from 0800 to $2400 \mathrm{~h}$ and at $0200,0400,0600$ and $0700 \mathrm{~h}$.

\section{Metabolite Estimations}

Two millilitres of blood was taken from the patients at each time point during the metabolic profile and added to cooled tubes containing $5 \% \mathrm{w} / \mathrm{v}$ perchloric acid. Precise amounts of blood and perchloric acid were determined gravimetrically. The tubes were then centrifuged twice and the supernatant separated within $10 \mathrm{~min}$, being stored at $-20^{\circ} \mathrm{C}$. Blood glucose [16], lactate [17], alanine [18], 3-hydroxybutyrate [19] and acetoacetate levels [20] were estimated using spectrophotometric techniques. Acetoacetate levels were measured within $24 \mathrm{~h}$ and other assays within 2 weeks. 3-hydroxybutyrate and acetoacetate levels at each sample time have been combined and expressed as total ketone bodies.

Statistical comparisons between groups have been made using Student's ' $t$ ' test (Welch approximation) [21].

\section{Results}

The mean 24-h levels for glucose, lactate, alanine and total ketone bodies are shown in Table 2 and the variations of these metabolites during the $24-\mathrm{h}$ period are shown in Figure 1. The diabetics tended to have higher glucose levels than non-diabetic women, although the differences were not significant. There was slightly more variation in blood glucose concentration during the day in the diabetics compared with the nondiabetic women, as assessed by comparison of the standard deviation of the means (group B - mean glucose $\mathrm{SD}=1.20$, range 0.75 to 3.44 ; group $\mathrm{A}$ - mean glucose $\mathrm{SD}=0.80$, range 0.62 to 0.97 , but dietary treatment did not improve the variation in blood glu- 

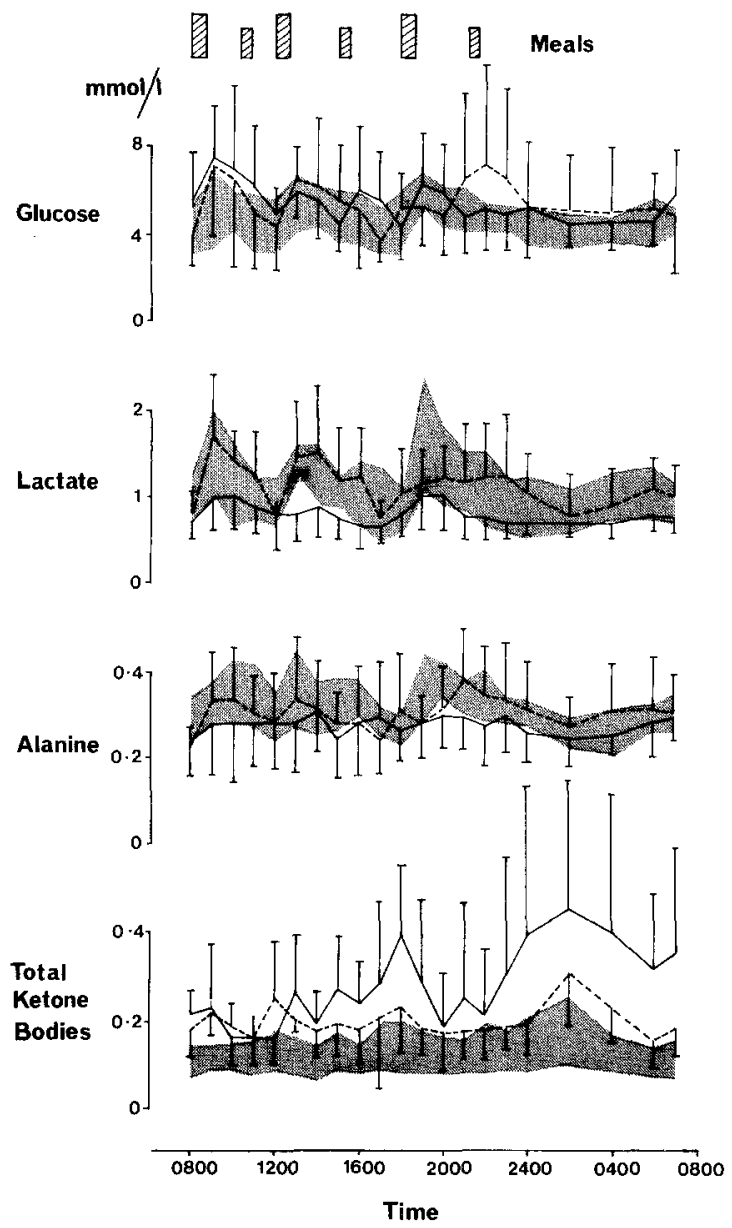

Fig. 1. Mean levels of blood glucose, lactate, alanine and total ketone bodies during the 24- $\mathrm{h}$ metabolic profiles in the third trimester of pregnancy in seven non-diabetic women (group A, shaded areas), seven gestational diabetics at diagnosis before dietary treatment (group B, broken lines and bars) and seven gestational diabetics during treatment with a $150 \mathrm{~g}$ carbohydrate restricted diet (group $\mathrm{C}$, solid lines and bars). Shaded areas and lines and bars represent mean levels \pm SD. Times of meals and snacks are represented by large and small hatched blocks respectively

cose during the day in the diabetics; group $\mathrm{C}$ - mean glucose $\mathrm{SD}=1.25$; range 0.62 to 2.97 ). Glucose levels tended to rise higher and remain elevated longer after meals in the diabetic group compared with the nondiabetic women, whereas the fasting glucose levels were not significantly different in each of the groups.

The lactate and alanine levels were similar in the non-diabetic women and the diabetics before treatment. Dietary restriction was associated with a fall in lactate levels $(0.05<p<0.10$ compared with untreated gestational diabetics). There was no significant reduction in alanine levels with dietary restriction. The reduction in mean 24-h lactate levels associated with dieting appeared to be related to the suppression of post-prandial rises of lactate.
Total ketone body levels were significantly elevated in the untreated diabetics compared with nondiabetic women $(p<0.01)$ and rose further in association with dietary treatment, although this did not reach significance possibly because of the greater variation in 24-h mean levels on diet (range 0.08 to $0.58 \mathrm{mmol} / 1$ ). Total ketone body levels in untreated diabetics were persistently raised throughout the day with peaks occurring at the normal times before meals and overnight. Dietary treatment was associated with a further increase in ketone body levels during the afternoon, evening and overnight.

\section{Discussion}

The gestational diabetics in this study had minor abnormalities in carbohydrate metabolism demonstrated by the oral glucose tolerance test (White Class A1) and these were also apparent during the 24 -h profiles, with a more pronounced and prolonged elevation of blood glucose after meals than in non-diabetic women. Although dietary treatment was not associated with significantly lower glucose levels, the patients were studied 2 weeks later in gestation, and since glucose tolerance is progressively impaired during pregnancy [22], dietary treatment could have prevented further deterioration of glucose homeostasis.

Increased levels of blood lactate normally occur after meals, due to increased glycolysis [23]. In the untreated gestational diabetics, marked increases in lactate occurred after meals paralleling closely the changes in blood glucose, which suggested that these women were able to secrete sufficient insulin to stimulate normal glycolysis. In the untreated gestational diabetics mean levels of blood lactate and alanine were very similar to those seen in non-diabetic women throughout the $24 \mathrm{~h}$. On dietary treatment there was a reduction in mean blood lactate over the $24 \mathrm{~h}$ and this was most marked post-prandially, which may indicate that carbohydrate intake had been effectively limited so that there was reduced glycolysis. Alanine levels showed a general reduction compared with non-diabetic women throughout the day but similar levels during the night. It is possible that during the day, with limited carbohydrate intake, these women maintained a higher level of gluconeogenesis than the non-diabetic women and hence utilised more alanine and lactate. However, during the night absence of carbohydrate would have occurred in both groups with the same resultant degree of gluconeogenesis.

Increased lipolysis and ketone body production after extended fasting in normal pregnancy has been termed accelerated starvation [24]. It might be expect- 
ed that diabetic patients would be more susceptible to this and indeed raised profiles of non-esterified fatty acids [25] and of fasting blood ketone bodies [26] have been observed in gestational diabetics. The persistently raised levels of ketone bodies in the untreated diabetics in this study throughout the day with peaks before meals and overnight is in keeping with accelerated starvation. It would seem unlikely to be due to relative insulin lack since carbohydrate restriction exacerbated the ketone body changes which were still more pronounced before meals and throughout the night. Whilst dietary treatment did not significantly increase mean ketone body levels, there was a marked trend towards this as well as to an increased variability of ketone body production throughout the day.

Metabolic factors other than blood glucose are known to be important in fetal development. Certain amino acids for instance have been shown to be potent stimuli to pancreatic insulin secretion [27] and may be a primary cause of fetal B cell hyperplasia characteristically seen in large infants of diabetic mothers. It has also been shown that small changes of non-esterified fatty acid and ketone levels can have marked effects on placental metabolism and fat deposition in vitro and these changes may be implicated in the in vivo changes in placental structure and function in diabetic mothers [8]. Clinically an association between maternal diabetes complicated by acetonuria and neuropsychological deficits in the children has been suggested to be present in both severe diabetes as well as in mild, including gestational diabetes [28], though other confirmatory studies are required. These results would seem to indicate that metabolic disturbances do occur in the presence of near normal glucose homeostasis even in the mildest gestational diabetics, which are exacerbated by dietary treatment and which could possibly influence fetal development. In treating gestational diabetics therefore, as in established diabetics, it is essential to obtain the best overall metabolic control. Treatment regimes however, which worsen some of the metabolic abnormalities of gestational diabetics would seem undesirable and carbohydrate restriction alone inappropriate. It is possible that insulin treatment with less severe dietary restriction may be a more rational approach to the management of these patients.

Acknowledgements. We would like to thank Professor I. D. Cooke, Mr. D. A. Aitken, Mr. W. Porter and Mr. T.Smith for allowing us to study patients under their care, and Professor C. N. Hales, Department of Clinical Biochemistry, Addenbrooke's Hospital, Cambridge for the metabolic estimations. We are also indebted to Dr. R. Kay, Department of Probability and Statistics, University of Sheffield, for statistical advice. J.M.P. is supported by a research grant from Novo Laboratories Limited.

\section{References}

1. O'Sullivan JB, Charles D, Mahan CM, Dandrow RV (1973) Gestational diabetes and perinatal mortality rate. Am J Obstet Gynecol 116:901-904

2. Sutherland HW, Stowers JM, Fisher PM (1979) Detection of chemical gestational diabetes. In: Sutherland HW, Stowers JM (eds) Carbohydrate metabolism in pregnancy and the newborn 1978. Springer-Verlag, Berlin Heidelberg New York, pp $436-461$

3. Carrington ER, Reardon HS (1958) Recognition and management of problems associated with prediabetes in pregnancy. $J$ Am Med Assoc 166: 245-249

4. Van Der Linden SJL, Mastboom JL (1971) Insulin treatment of latent and potential diabetes during pregnancy. J Obstet Gynaecol Br Commonw 78:924-926

5. Gabbe SG, Mestman JH, Freeman RK, Anderson GV, Lowensohn RJ (1977) Management and outcome of class A diabetes mellitus. Am J Obstet Gynecol 127: 465-469

6. Pedersen J (1977) The pregnant diabetic and her newborn. Munksgaard, Copenhagen, pp 211-220

7. Szabo AJ, Szabo O (1974) Placental free-fatty-acid transfer and fetal adipose tissue development: an explanation of fetal adiposity in infants of diabetic mothers. Lancet 2: 498-499

8. Freinkel N, Phelps RL, Metzger BE (1979) Intermediary metabolism during normal pregnancy. In: Sutherland HW, Stowers JM (eds) Carbohydrate metabolism in pregnancy and the newborn 1978. Springer-Verlag, Berlin Heidelberg New York, pp $1-31$

9. Milner RDG, de Gasparo M, Milner GR, Wirdnam PK (1978) Amino acids and development of the beta cell. In: Sutherland $\mathrm{HW}$, Stowers JM (eds) Carbohydrate metabolism in pregnancy and the newborn 1978. Springer-Verlag, Berlin Heidelberg New York pp 132-151

10. Szabo AJ, Oppermann W, Hanover B, Gugliucci C, Szabo O (1975) Fetal adipose tissue development: relationship to maternal free fatty acid levels. In: Camerini-Davalos RA, Cole HS (eds) Early diabetes in early life. Academic Press, New York, pp $167-176$

11. Metzger BE, Phelps RL, Freinkel N (1976) Correlation of plasma amino acids with fetal macrosomia in gestational diabetes. Clin Res 24: 502

12. Karlsson K, Kjellmer I (1972) The outcome of diabetic pregnancies in relation to the mother's blood sugar level. Am J Obstet Gynecol 112:213-220

13. White $P$ (1971) Pregnancy and diabetes. In: Marble A, White $P$, Bradley RF, Krall LP (eds) Joslin's diabetes mellitus, 11 th edn. Lea and Febiger, Philadelphia, pp 581-598

14. Fitzgerald MG, Keen H (1964) Diagnostic classification of diabetes. Br Med J 1: 1568

15. Hadden DR (1979) Asymptomatic diabetes in pregnancy. In: Sutherland HW, Stowers JM (eds) Carbohydrate metabolism in pregnancy and the newborn 1978. Springer-Verlag, Berlin Heidelberg New York, pp 407-424

16. Bergmeyer HU, Bernt E, Schmidt F, Stork H (1974) D glucose. Determination with hexokinase and glucose-6-phosphate dehydrogenase. In: Bergmeyer HU (ed) Methods of enzymatic analysis. Academic Press, New York, pp 1196-1201

17. Gutmann I, Wahlefeld AW (1974) L- (+)-lactate. Determination with lactate dehydrogenase and NAD. In: Bergmeyer HU (ed) Methods of enzymatic analysis. Academic Press, New York, pp 1464 1468

18. Williamson DH (1974) L-alanine determination with alanine dehydrogenase. In: Bergmeyer HU (ed) Methods of enzymatic analysis. Academic Press, New York, pp 1679-1682

19. Williamson DH, Mellanby J (1974) D-( - )-3-hydroxybutyrate. 
In: Bergmeyer HU (ed) Methods of enzymatic analysis. Academic Press, New York, pp 1836-1839

20. Price CP, Lloyd B, Alberti KGMM (1977) A kinetic spectrophotometric assay for the rapid determination of acetoacetate in blood. Clin Chem 23: 1893-1897

21. Armitage P (1971) Statistical methods in medical research. Blackwell Scientific Publications, Oxford London Edinburgh Melbourne, $\mathrm{p} 123$

22. Lind T, Billewicz WZ, Brown G(1973) A serial study of changes occurring in the oral glucose tolerance test during pregnancy. $\mathrm{J}$ Obstet Gynaecol Br Commonw 80: 1033-1039

23. Alberti KGMM, Dornhorst A, Rowe AS (1975) Metabolic rhythms in normal and diabetic man. Isr J Med Sci 11: 571-580

24. Ravnikar V, Metzger BE, Freinkel N (1978) Is there a risk of "accelerated starvation" in normal human pregnancy? Diabetes $27: 463$

25. Gillmer MDG, Beard RW, Oakley NW, Brooke FM, Elphick MC, Hull D (1977) Diurnal plasma free fatty acid profiles in normal and diabetic pregnancies. Br Med J 2:670-673
26. Persson B, Lunell NO (1975) Metabolic control in diabetic pregnancies. Am J Obstet Gynecol 122: 737-745

27. Milner RDG, Ashworth MA, Barson AJ (1972) Insulin release from human fetal pancreas in response to glucose, leucine and arginine. J Endocrinol 52:497-505

28. Churchill JA, Berendes HW, Nemore J (1969) Neuropsychological deficits in children of diabetic mothers. Am J Obstet Gynecol 105: 257-268

29. Weights of insured persons in the United States associated with lowest mortality (1959) Stat Bull Metrop Life Insur Co, 40

Received: 22 April 1980

and in revised form: 9 January 1981

Dr. D. R. Cullen

Royal Hallamshire Hospital

Glossop Road

Sheffield, S10 2JF, UK 